Short Communication

\title{
Integrated Capacitive and Resistive Humidity Transduction via Surface Type Nickel Phthalocyanine Based Sensor
}

\author{
Zubair Ahmad ${ }^{1, *}$, Farid Touati ${ }^{2}$, Qayyum Zafar ${ }^{3}$ and Mutabar Shah ${ }^{4}$ \\ ${ }^{1}$ Center for Advanced Materials (CAM), Qatar University, P. O. Box 2713, Doha, Qatar. \\ ${ }^{2}$ Department of Electrical Engineering, College of Engineering, Qatar University, P. O. Box 2713, \\ Doha, Qatar. \\ ${ }^{3}$ Low Dimensional Materials Research Centre, Department of Physics, University of Malaya, Kuala \\ Lumpur 50603, Malaysia \\ ${ }^{4}$ Institute of Physics and Electronics, University of Peshawar, 25120 Peshawar, Khyber Pakhtunkhwa, \\ Pakistan \\ *E-mail: zubairtarar@qu.edu.qa
}

doi: $10.20964 / 2017.04 .21$

Received: 6 December 2016 / Accepted: 8 February 2017 / Published: 12 March 2017

This paper reports the study of an organic semiconductor nickel phthalocyanine (NiPc) based thin film surface-type integrated capacitive and resistive type humidity sensor. The capacitance and resistance of the fabricated devices were evaluated at room temperature in the relative humidity $(\mathrm{RH})$ range of 3595\% and 35-75\% RH, respectively. In general, an increase in capacitance and decrease in resistance of the $\mathrm{Ag} / \mathrm{NiPc} / \mathrm{Ag}$ sensor was observed with the rise in humidity level. Humidity dependent capacitance and resistance properties of this sensor make it attractive for use in humidity sensors. The response and recovery characteristic of the humidity sensor were also investigated.

Keywords: surface-type humidity sensor, capacitance, resistance, nickel phthalocyanine, environmental monitoring, humidity, organic semiconductor.

\section{$\underline{\text { FULL TEXT }}$}

(C) 2017 The Authors. Published by ESG (www.electrochemsci.org). This article is an open access article distributed under the terms and conditions of the Creative Commons Attribution license (http://creativecommons.org/licenses/by/4.0/). 